\title{
Advantages of gadolinium based ultrasmall nanoparticles vs molecular gadolinium chelates for radiotherapy guided by MRI for glioma treatment
}

\author{
Géraldine Le Duc ${ }^{1}$, Stéphane Roux², Amandine Paruta-Tuarez ${ }^{3}$, Sandrine Dufort ${ }^{4}$, Elke Brauer $^{1}$, Arthur Marais ${ }^{3}$,
} Charles Truillet ${ }^{3}$, Lucie Sancey ${ }^{3}$, Pascal Perriat ${ }^{5}$, François Lux ${ }^{3^{*}}$ and Olivier Tillement ${ }^{3}$

\author{
* Correspondence: \\ francois.lux@unive-lyon1.fr \\ ${ }^{3}$ Institut Lumière Matière, UMR 5306 \\ Université Lyon 1 - CNRS, Team \\ FENNEC, Université de Lyon, 69622 \\ Villeurbanne, Cedex, France \\ Full list of author information is \\ available at the end of the article
}

\begin{abstract}
AGuIX nanoparticles are formed of a polysiloxane network surrounded by gadolinium chelates. They present several characteristics. They are easy to produce, they present very small hydrodynamic diameters $(<5 \mathrm{~nm})$ and they are biodegradable through hydrolysis of siloxane bonds. Such degradation was evaluated in diluted conditions at physiological pH by dynamic light scattering and relaxometry. AGuIX nanoparticles are also known as positive contrast agents and efficient radiosensitizers. The aim of this paper is to compare their efficiency for magnetic resonance imaging and radiosensitization to those of the commercial gadolinium based molecular agent: DOTAREM ${ }^{\oplus}$. An experiment with healthy animals was conducted and the MRI pictures we obtained show a better contrast with the AgulX compared to the DOTAREM ${ }^{\circledast}$ for the same amount of injected gadolinium in the animal. The better contrast obtained after injection of Aguix than DOTAREM ${ }^{\varpi}$ is due to a higher longitudinal relaxivity and a residential time in the blood circulation that is two times higher. A fast and large increase in the contrast is also observed by MRI after an intravenous injection of the AGuIX in $9 \mathrm{~L}$ gliosarcoma bearing rats, and a plateau is reached seven minutes after the injection.

We established a radiotherapy protocol consisting of an irradiation by microbeam radiation therapy 20 minutes after the injection of a specific quantity of gadolinium. After microbeam radiation therapy, no notable difference in median survival time was observed in the presence or absence of gadolinium chelates (38 and 44 days respectively). In comparison, the median survival time is increased to 102.5 days with AGulX particles showing their interest in this nanomedicine protocol. This remarkable radiosensitizing effect could be explained by the persistent tumor uptake of the particles, inducing a significant nanoscale dose deposition under irradiation.
\end{abstract}

Keywords: 3-10 : Gadolinium; MRI; DOTA; Radiosensitization; Nanoparticles

\section{Background}

As emphasized by J. N. Long et al. in a recent review [1], molecular gadolinium chelates and in particular those involving 1,4,7,10-tetraazacyclododecane-1,4,7,10-tetraaccetic acid (DOTA) have been extensively developed and used in biomedical imaging for the last 25 years. First used for magnetic resonance imaging (MRI), DOTA $\left(\mathrm{Gd}^{3+}\right)$ (commercially known as DOTAREM ${ }^{\circ}$ ) offers the advantage of a better thermodynamic association constant as well as lower dissociation kinetic rates in comparison to acyclic

(c) 2014 Le Duc et al.; licensee Springer. This is an Open Access article distributed under the terms of the Creative Commons Attribution License (http://creativecommons.org/licenses/by/4.0), which permits unrestricted use, distribution, and reproduction in any medium, provided the original work is properly credited. 
ligands [2]. These characteristics are essential to safely use a gadolinium-based contrast agent and avoid nephrogenic systemic fibrosis (NFS) [3] that might be induced by the in vivo demetallation of gadolinium. DOTA and DOTA derivatives can also be used for the chelation of radioactive isotopes $\left(e . g .{ }^{111} \mathrm{In}\right.$ or $\left.{ }^{64} \mathrm{Cu}\right)$ to perform single photon emission computed tomography (SPECT) [4] or positron emission tomography (PET) [5]. They can be coupled to various types of targeting ligands (e.g. antibodies [6], peptides [7], aptamers [8]) to render the imaging more sensitive and efficient. In line with the recent development of fused instruments to perform multimodal imaging (PET/MRI (Magnetic Resonance Imaging), SPECT/CT or PET/CT (computed tomography), Fluorescence/MRI) [9], DOTA based $\mathrm{Gd}^{3+}$ complexes can be associated with other imaging agents, such as radionuclide chelators or organic luminescent probes [10-12].

Another strategy to enhance the imaging contrast and to permit multimodal imaging as well as theranostic applications has been proposed recently. It consists in coupling the chelating species to the surface of nanoparticles $[13,14]$, or to incorporate them into nanostructures [15]. As MRI suffers from low sensitivity [16], coupling gadolinium chelates to nanostructures is an advantage for MRI because it enhances the longitudinal relaxivity both per object (by grafting multiple chelates on one object) and per gadolinium (by increasing the rotational correlation time) [17]. Another advantage of using nanoparticles is that they do not present any extravasation from normal vessels and are accumulated passively in tumors via the enhanced permeability and retention (EPR) effect [18]. Finally, the use of efficient MRI contrast agents provides a better delineation of the tumor and consequently a better image guidance for further radiotherapy protocol. The clinical interest for image guided radiation therapy (IGRT) is for example emphasized by the partnership between Elekta (radiotherapy systems manufacturers) and Philips (medical imaging specialists) [19]. In this context, gadolinium is playing an important role because of its intrinsically properties for MRI and because of its relatively high atomic number value $(Z=64)$. This is important since many molecules [20] containing bromine $(Z=35)$, iodide $(Z=53)$, gadolinium or platinum $(Z=78)$ or nanoparticles [21] made with gold $(Z=79)$ have shown great potential in radiosensitization. Since the pioneering work of Hainfeld et al. [21] a large number of experimental reports using particles with different photon source energies as well as different cell lines confirms the interest in nanoparticles to enhance the clinical irradiation efficiency [22,23]. For the moment, the most studied gadolinium-based radiosensitizer is Motexafin Gadolinium (MGd). It contains a porphyrin like macrocycle that chelates gadolinium. MGd can be detected by MRI and is currently in the phase III of clinical development as a radiosensitizer for irradiation of brain tumors [24-26]. As theoretical work and experiments suggest that heavy elements in nanoparticles improve radiosensitization [22], our team has developed a family of ultrasmall gadolinium based nanoparticle for MRI and radiosensitization called AGuIX (Activation Guided by Irradiation by X-rays). Two main types of nanoparticles were proposed that present very similar in vivo behaviors. The first nanoparticles consist of a polysiloxane core coated with DTPA (Diethylene Triamine Pentaacetic Acid) [27] and have demonstrated their potential for IGRT. To completely prevent any release of gadolinium, a new generation of nanoparticles incorporating DOTA was proposed [28,29]. For their synthesis, a DOTA derivative: DOTAGA [30,31] (GA = Glutaric Acid) was used for the grafting on the nanoparticle. The additional arm of this macrocycle is used to form an amide bond leaves eight 
coordination atoms for the chelation of gadolinium as in molecular DOTA. This coordination mode leads to a similar association constant towards gadolinium for the DOTAGA grafted on the nanoparticle compared to molecular DOTA towards gadolinium ( $\log \beta=24.78$ and 25.58 respectively) [29]. Interestingly, the two types of nanoparticles have very similar physico-chemical properties, radiosensitizing properties and in vivo biodistribution profiles. The aim of this paper is to demonstrate the interest of these nanoparticles supporting gadolinium chelates for the treatment of glioma by IGRT compared to using small gadolinium chelates.

\section{Methods}

\section{Chemicals}

Gadolinium chloride hexahydrate ( $\left.\left[\mathrm{GdCl}_{3}, 6 \mathrm{H}_{2} \mathrm{O}\right], 99.999 \%\right)$, sodium hydroxide $(\mathrm{NaOH}$, 99.99\%), tetraethyl orthosilicate $\left(\mathrm{Si}_{(}\left(\mathrm{OC}_{2} \mathrm{H}_{5}\right)_{4}, \mathrm{TEOS}, 98 \%\right)$, aminopropyl-triethoxysilane $\left(\mathrm{H}_{2} \mathrm{~N}\left(\mathrm{CH}_{2}\right)_{3}-\mathrm{Si}\left(\mathrm{OC}_{2} \mathrm{H}_{5}\right)_{3}\right.$, APTES, 99\%), triethylamine (TEA, 99.5\%), 4-(2-hydroxyethyl)1-piperazineethanesulfonic acid (HEPES, 99.5\%), sodium hydroxide ( $\mathrm{NaOH}, 99.99 \%)$, sodium chloride $(\mathrm{NaCl}, 99.8 \%)$, calcium chloride $\left(\mathrm{CaCl}_{2}, 99 \%\right)$, the bovine serum albumin and dimethyl sulfoxide (DMSO, 99.5\%) were purchased from Aldrich Chemicals (France). Diethylene glycol (DEG, 99\%) was purchased from SDS Carlo Erba (France). Acetone (reagent grade) was purchased from Sodipro (France) and was used in the same conditions as received. 1,4,7,10-tetraazacyclododecane-1-glutaric anhydride-4,7,10-triacetic acid (DOTAGA) was furnished by CheMatech (Dijon, France). Gadolinium oxide cores were furnished by Nano-H S.A.S (Saint-Quentin Fallavier, France). Only milli-Q water was used for the preparation of aqueous solutions of nanoparticles.

\section{Characterization}

\section{DLS (Dynamic Light Scattering) size measurement}

Direct measurements of the size distribution (in DEG) or after dilution (at $10 \mathrm{mM}$ in $\left[\mathrm{Gd}^{3+}\right]$ for water) of the nanoparticles were performed via Zetasizer NanoS DLS (laser He-Ne $633 \mathrm{~nm}$ ) from Malvern Instrument.

\section{$\zeta$-potential measurements}

Direct determination of the $\zeta$-potential of the hybrid nanoparticles were performed via a Zetasizer NanoS from Malvern Instruments. Prior to the experiment, the nanoparticles were diluted in an aqueous solution containing $0.005 \mathrm{M}$ in $\mathrm{NaCl}$ and adjusted to the desired $\mathrm{pH}$.

\section{Inductively coupled plasma-atomic emission spectrometry (ICP-AES) analysis}

Determination of the gadolinium content in a sample was performed by ICP-AES analysis (with a Varian 710-ES spectrometer). Before measuring gadolinium concentration, samples of colloidal solution were dissolved in concentrated nitric acid for 24 hours. The samples were then diluted with water, until the nitric acid concentration in water reached $5 \%$. Chemical analyses were also performed on the as-prepared samples at the Service Central d'Analyses du CNRS (Solaize, France) by ICP-AES, and enabled determining the $\mathrm{C}, \mathrm{N}, \mathrm{Si}$ contents with a precision of $0.5 \%$. 


\section{Relaxometry}

Relaxation time measurements were performed using a Bruker Minispec MQ60 NMR analyser, operating at $1.4 \mathrm{~T}$ magnetic field.

High performance liquid chromatography (HPLC)

Gradient HPLC analysis was done by using Shimadzu Prominence series UFLC system with a CBM-20A controller bus module, a LC-20 AD liquid chromatograph, a CTO-20A column oven and a SPD-20A UV-visible detector. UV-visible absorption was measured at $295 \mathrm{~nm}$. $20 \mu \mathrm{L}$ of sample were loaded in the solvent injection ratio: 95\% solvent A - 5\% solvent B (A = Milli-Q water/TFA 99.9:0.1 v/v; B = $\mathrm{CH}_{3} \mathrm{CN} / \mathrm{Milli} \mathrm{Q}$ water/ TFA 90:9.9:0.1 v/v/v) onto a Jupiter C4 column $(150 \times 4.60 \mathrm{~mm}, 5 \mu \mathrm{m}, 300 \AA$, Phenomenex) at a flow rate of $1 \mathrm{~mL} / \mathrm{min}$ over $5 \mathrm{~min}$. In a second step, samples were eluted by a gradient developed from 5 to $90 \%$ of solvent B in solvent A over $15 \mathrm{~min}$. The concentration of solvent B was maintained over $5 \mathrm{~min}$. Then, the concentration of solvent B was decreased to $5 \%$ over a period of $5 \mathrm{~min}$ to re-equilibrate the system, followed by additional $5 \mathrm{~min}$ at this final concentration. Before each sample measurement, a baseline was performed following the same conditions by loading Milli-Q water into the injection loop.

\section{Particles synthesis}

\section{Preparation of gadolinium oxide cores [32]}

A solution was prepared by dissolving $167.3 \mathrm{~g}$ of $\left[\mathrm{GdCl}_{3}, 6 \mathrm{H}_{2} \mathrm{O}\right]$ in $3 \mathrm{~L}$ of DEG at room temperature. The solution is then stirred for 3 hours at $140^{\circ} \mathrm{C}$. Afterwards, $44.5 \mathrm{~mL}$ of sodium hydroxide solution $(10 \mathrm{M})$ is added to the solution. This final solution is stirred for 5 hours at $180^{\circ} \mathrm{C}$ before cooling and stirring for 12 hours at ambient temperature. The gadolinium oxide cores displayed hydrodynamic diameters of $1.7 \pm$ $0.5 \mathrm{~nm}$.

\section{Encapsulation of gadolinium oxide cores by polysiloxane}

The polysiloxane shell is ensured by sol-gel process by addition of silane precursors. First, a solution containing 1.6 L of DEG, $51.42 \mathrm{~mL}$ of TEOS and $80.61 \mathrm{~mL}$ of APTES is slowly added (during 96 hours) to the precedent solution under stirring at $40^{\circ} \mathrm{C}$. One hour after the end of the addition of the silane precursors, a second solution of $190 \mathrm{~mL}$ of DEG, $43.1 \mathrm{~mL}$ of water and $6.94 \mathrm{~mL}$ of TEA is added under stirring at $40^{\circ} \mathrm{C}$ during 96 hours. At the end of the second addition, the solution is stirred for 72 hours at $40^{\circ} \mathrm{C}$ and finally for 12 hours at ambient temperature. The gadolinium oxide cores coated by the polysiloxane displayed hydrodynamic diameter of $2.6 \pm 1.0 \mathrm{~nm}$.

\section{Covalent grafting of DOTAGA on the nanoparticles}

$163.7 \mathrm{~g}$ of DOTAGA anhydride are then added to the core-shell nanoparticles in DEG. The resulting solution is stirred for 72 hours at room temperature.

\section{Purification}

17.5 $\mathrm{L}$ of acetone are added to the solution to precipitate the nanoparticles that are filtered under vacuum before dispersion in water. The solution is stirred for one hour at $\mathrm{pH} 2$ before remaining acetone is removed by evaporation. The nanoparticles are 
then purified by tangential filtration through $5 \mathrm{kDa}$ membrane. The solution is stirred at $\mathrm{pH} 5$ for 12 hours before another tangential filtration through $5 \mathrm{kDa}$ membrane after addition of sodium hydroxide solution to reach $\mathrm{pH}$ 7.4. Afterward, the solution is filtered twice through a $1.2 \mu \mathrm{m}$ and then $0.2 \mu \mathrm{m}$ syringe filters to remove the largest impurities. Finally, the nanoparticles are freeze-dried and can be stored for months without alterations. After dispersion in water, the AGuIX nanoparticles display hydrodynamic diameter of $2.2 \pm 1 \mathrm{~nm}$. Elementary analysis found (weight percent) $\mathrm{C}, 26.84 ; \mathrm{N}, 7.79 ; \mathrm{Gd}, 13.83 ; \mathrm{Si}, 10.79$. An average mass of $8.7 \pm 1 \mathrm{kDa}$ is obtained by mass spectrometry. The longitudinal relaxivity $\left(\mathrm{r}_{1}\right)$ is $11.5 \mathrm{mM}^{-1} \cdot \mathrm{s}^{-1}$ at 1.4 $\mathrm{T}$. The nanoparticles display an isoelectric point at $\mathrm{pH} 7.5 \pm 0.5$. About $50 \mathrm{~g}$ of nanoparticles are obtained at the end of the synthesis. HPLC chromatogram, with UV absorption detection at $295 \mathrm{~nm}$, shows a retention time of $10 \mathrm{~min}$ for the nanoparticles.

\section{Imaging and MRT procedure}

All operative procedures related to experiments on glioma bearing rats strictly conformed to the French government regulations with licenses 380825 and B3818510002 and were approved by the internal evaluation committee for animal welfare and rights of the ESRF. All operative procedures related to MR on healthy mice strictly conformed to the Guidelines of the French Government with licenses 380324 and A3818510002 for MRI on healthy mice. All experiments were performed under anesthesia with the following parameters: $5 \%$ isoflurane for induction and intraperitoneal injection of xylazine/ketamine $\left(64.5 / 5.4 \mathrm{mg} \cdot \mathrm{kg}^{-1}\right)$ for maintenance.

\section{Brain tumor inoculation}

The 9 L gliosarcoma (9LGS) cells were implanted in the brain of male fisher F344 rats (Charles River, France) [33]. Anesthetized animals were placed on stereotactic frame, and $10^{4}$ 9LGS cells were suspended in $1 \mu \mathrm{L}$ culture medium with antibiotics before to be injected through a burr hole in the right caudate nucleus $(3.5 \mathrm{~mm}$ lateral to the bregma, $6 \mathrm{~mm}$ below the skull surface).

\section{Preparation of injectable solution}

After tangential filtration, a concentrated colloid (AGuIX in water, $\left[\mathrm{Gd}^{3+}\right]=100 \mathrm{mM}$ ) was diluted by aqueous solution containing $\mathrm{NaCl}$ and hepes in order to obtain an intravenous use solution $\left(\left[\mathrm{Gd}^{3+}\right]=40 \mathrm{mM},[\mathrm{NaCl}]=145 \mathrm{mM}\right.$, [hepes $\left.]=10 \mathrm{mM}\right)$. The $\mathrm{pH}$ was adjusted to 7.4. Before use, this solution was filtered onto syringe filter with nylon membrane (pore diameter $0.22 \mu \mathrm{m}$ ). The chelate used was DOTAREM ${ }^{\circ}$ (laboratories Guerbet, Aulnay sous Bois France, $0,5 \mathrm{mM} / \mathrm{mL}$ ) as available in MRI units.

\section{Drug injection}

The aqueous AGuIX $\left(\left[\mathrm{Gd}^{3+}\right]=40 \mathrm{mM},[\mathrm{NaCl}]=145 \mathrm{mM}\right.$, [hepes $\left.]=10 \mathrm{mM}\right)$ colloid was manually injected in the saphena vein at $1.4 \mathrm{~mL}$ volume using a $2 \mathrm{~mL}$ syringe and a $26 \mathrm{G}$ needle. The gadolinium chelates were injected via the saphena vein according 2 protocols. First, a series of rats received an injection of a colloidal solution at the concentration of $1 \mathrm{M}$ in $\mathrm{Gd}$, i.e. twice the concentration routinely used in clinical conditions $(0.5 \mathrm{mM})$. The volume injected was of $56 \mu \mathrm{L}$ which corresponds to a 
quantity of Gd (56 $\mu \mathrm{mol})$ similar to those currently injected. Second, another series of rats received a $1.4 \mathrm{~mL}$ DOTAREM $^{\circ}$ injection diluted in physiological serum until $40 \mathrm{mM}$ (to establish a direct comparison with the nanoparticles, the quantity of $\mathrm{Gd}$ injected being the same than previously).

\section{MR imaging}

The MR imaging took place at Grenoble Institute of Neuroscience (GIN) using a 7 Tesla Imaging system (Biospec, Bruker, Erlangen Germany) equipped with a $400 \mathrm{mM} / \mathrm{T}$ gradient. The images were made 14 days after implantation, and the rats were injected in the saphena vein with $1.4 \mathrm{ml}$ of a Gd based particles solution at $40 \mathrm{mM}$ in gadolinium. Images were acquired at fixed times after injection using a T2 weighted Turbo RARE SE sequence $(\mathrm{TR}=4,000 \mathrm{~ms}, \mathrm{TE}=33 \mathrm{~ms}, \mathrm{FOV}=3 \mathrm{~cm}$, Resolution $=0,12 \mathrm{~mm}$, $\mathrm{ST}=1 \mathrm{~mm})$ and a T1 weighted FLASH sequence $(\mathrm{TR}=840 \mathrm{~ms}, \mathrm{TE}=10,804 \mathrm{~ms}$, FOV $=3 \mathrm{~cm}$, Resolution $+0,12 \mathrm{~mm}, \mathrm{ST}=1 \mathrm{~mm})$.

\section{Radiation source and microbeam radiation therapy (MRT) set-up}

Irradiations were performed at the ID17 Biomedical Beamline of the European Synchrotron Radiation Facility (ESRF, France) using X-rays emitted tangentially from electron bunches circulating in a storage ring. The wiggler produces a wide spectrum of photons which extends, after filtration, from 50 over $350 \mathrm{keV}$ (median energy: $90 \mathrm{keV}$ ). The mean dose rate was then $62 \mathrm{~Gy} \cdot \mathrm{mA}^{-1} \cdot \mathrm{s}^{-1}$ allowing very fast irradiation. The quasilaminar beam was micro-fractionated into an array of 41 rectangular and quasi-parallel 50 microns width microbeams, separated by 200 microns centre to centre. The setup was performed by using the ESRF Multislit Collimator, positioned $33 \mathrm{~m}$ from the photon source, and $80 \mathrm{~cm}$ upstream from the rat holder. Ten days after tumor inoculation, the animals were positioned prone on a Kappatype goniometer (Huber, Germany) in front of the X-rays source, on a homemade Plexiglas frame, and the alignment into the beam was performed using live cameras. The contention of the rats was performed by a teeth bar, while the animals were under anaesthesia. They were received a lateral irradiation, from their anatomical right to left side, followed by an antero-posterior irradiation (cross fired configuration). The beam was shaped into a field of irradiation of $10 \mathrm{~mm}$ horizontal, and the animals were scanned vertically over $10 \mathrm{~mm}$ through the beam after opening of the shutter. Although the total procedure lasted about $2 \mathrm{~min}$, for each rat, the irradiation time is around $2 \mathrm{~s}$. Animal immobility during exposure was checked on three control video screens located in the control hutch. The microbeam dose at the tumor (i.e. $7 \mathrm{~mm}$ of depth from lateral side) was $400 \mathrm{~Gy}$, the valley dose was 18.6 Gy as computed by Monte Carlo simulations. The spatial configuration of irradiation was checked by radiochromic films (Gafchromic, HD-810) exposed in front of rats.

\section{Survival analysis}

The survivals of animals were represented on Kaplan - Meier curves and compared using the log-rank test; the Median Survival time (MeST) postimplantation was calculated (Prism, GraphPad Software, San-Diego, USA). 


\section{Results and discussion}

\section{Synthesis}

A protocol for the synthesis of AGuIX has been previously published [28,29]. A scaleup synthesis has been developed in order to produce larger quantities of nanoparticles for in vivo applications and further potential clinical applications. The first step is the formation of a gadolinium oxide core by a slow addition of $\mathrm{NaOH}$ solution on gadolinium trichloride previously dissolved in diethylene glycol at high temperature. The gadolinium oxide cores are then coated by a polysiloxane shell by addition of suitable silane precursors. DOTAGA anhydride is then added to the nanoparticles; the chelate is grafted by a peptide bond on the surface of the polysiloxane matrix. The dispersion of these nanoparticles in water leads to the dissolution of the gadolinium oxide core which is induced by the chelation of the gadolinium by the ligands. As a result, ultrasmall nanoparticles are obtained, displaying hydrodynamic diameter of $2.1 \pm 1 \mathrm{~nm}$ and a mass of $8.7 \pm 1 \mathrm{kDa}$ [29]. They are composed of a polysiloxane core surrounded by about ten gadolinium chelates displaying hydrodynamic diameter of $2.1 \pm 1 \mathrm{~nm}$ and a mass of $8.7 \pm 1 \mathrm{kDa}$.

\section{Characterization of the biodegradation}

The nanoparticles present biodegradable properties in diluted or basic media. A cleavage of the oxygen-silicon bonds is observed in these conditions, leading to smaller nanoparticles that possess the same characteristics than the initial ones: they are also made of polysiloxane and surrounded by gadolinium chelates [34]. In order to characterize the dissolution process, the freeze-dried nanoparticles have been dispersed at $50 \mathrm{mM}\left(\right.$ in $\mathrm{Gd}^{3+}$ ) at physiological $\mathrm{pH}$ in a solution containing $0.1 \mathrm{M}$ of sodium chloride and $1.5 \mathrm{mM}$ of calcium chloride and stirred at this concentration for one hour to permit homogeneous dispersion of the nanoparticles. They are diluted $\left(\left[\mathrm{Gd}^{3+}\right]=\right.$ $2.5 \mathrm{mM}$ ) in a solution containing $0.1 \mathrm{M}$ of sodium chloride and $1.5 \mathrm{mM}$ of calcium chloride. The hydrodynamic diameter obtained by DLS has been plotted versus time for a temperature of $37^{\circ} \mathrm{C}$ (See Figure 1). The curve has been fitted by a monoexponential decay curve and lead to a half-life of about 19.6 minutes. Moreover, the degradation can be followed by relaxometry thanks to the longitudinal relaxivity $\left(r_{1}\right)$, which is higher for greater nanoparticles mass due to an increase in the rotational correlation time [17]. Temporal evolution of $r_{1}$ per gadolinium has been plotted after

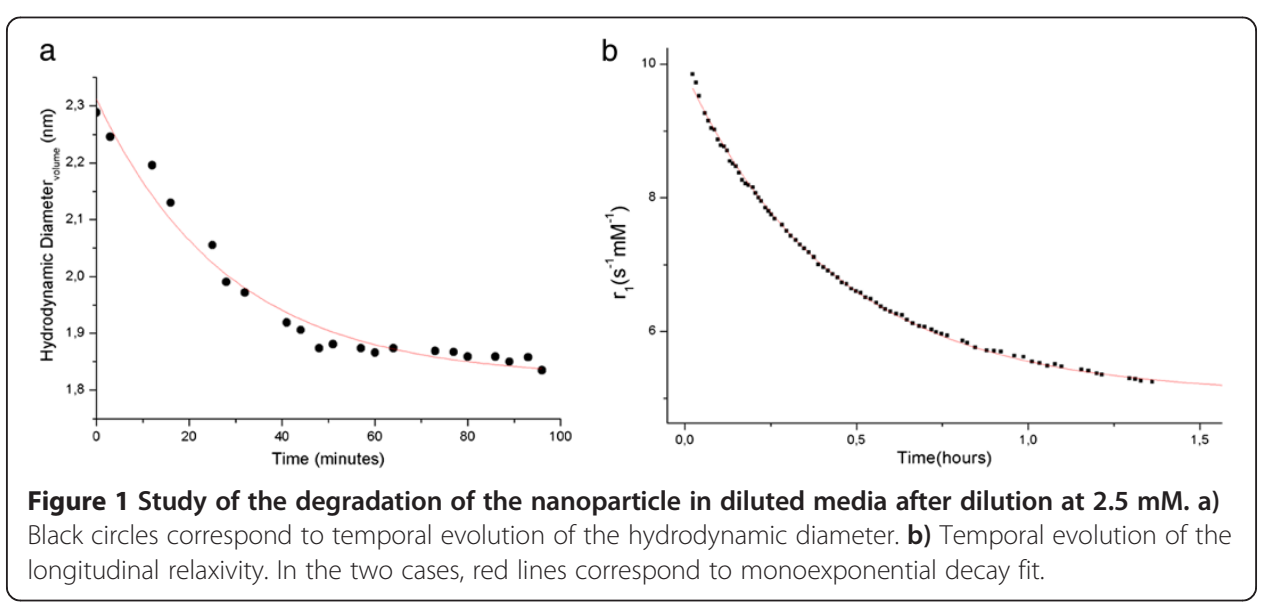


dilution at $2.5 \mathrm{mM}$ in bovine serum albumin. This serum has the same main properties than human serum (See Figure 1). After fitting hydrodynamic diameter and relaxivity by a mono-exponential decay curve, a similar half-life of 17.9 minutes is observed, indicating a non-negligible degradation in diluted solutions close to in vivo conditions. The degradation life-time is close to the order of magnitude of the residence time, which may explain the observed efficiency of the renal elimination.

\section{MRI study}

\section{On healthy animals}

The AGuIX nanoparticles have been intravenously injected ( $80 \mu \mathrm{L}$ at $40 \mathrm{mM}$ in Gd) on 8-weeks-old c57B1/6 J mice and have been followed by MRI at $7 \mathrm{~T}\left(\mathrm{r}_{1}=6 \mathrm{mmol}^{-1} \cdot \mathrm{s}^{-1}\right)$ [28]. A rapid highlight of the kidney and then of the bladder is observed (about 5 and 25 minutes after the intravenous injection of the nanoparticles respectively). A similar dose of DOTAREM ${ }^{\circ}(80 \mu \mathrm{L}$ at $40 \mathrm{mM}$ in Gd) was injected in the mice and the residence time of the nanoparticles in the blood was found to be about two times higher for AGuIX than for DOTAREM ${ }^{\circ}$ (13.2 minutes for AGuIX versus 6.8 min for DOTAREM ${ }^{\circ}$ ). This higher residence time leads to a larger imaging window for the nanoparticles in comparison to the chelates. Angiography images show a clear highlight of the blood brain vessels with a better contrast for the nanoparticles due to the higher relaxivity and the longer residence time in the blood circulation. Interestingly, the nanoparticles are eliminated from the kidney according to a multi-exponential law. The entire nanoparticles are eliminated more slowly than the partially degraded that pass directly from the kidneys to the bladder. The full nanoparticles are first taken up by renal cells of the cortex region before complete elimination.

\section{On tumor bearing animals}

Previous studies on brain glioma bearing rats have shown that gadolinium chelates injected intravenously can provide clear highlights of the tumors [35]. Interestingly, the contrast to noise ratio (CNR) is maximal 1-3 minutes after the injection and decreases very rapidly. For example, U. I. Attenberger et al. have injected GADOVIST ${ }^{\oplus}$, DOTAREM $^{\circ}$ and MAGNEVIST $^{\bullet}$ in glioma bearing rats [35]. For DOTAREM ${ }^{\circ}$, they obtained tumor Signal to Noise Ratio (SNR) on a $1.5 \mathrm{~T}$ apparatus of $30.9 \pm 4.4,54.1 \pm 3.8$, $51.6 \pm 5.9,45.7 \pm 2.5,44.1 \pm 2.2$ and $41.4 \pm 1.5$ (before injection and $1 \mathrm{~min}, 3 \mathrm{~min}$, $5 \mathrm{~min}, 7 \mathrm{~min}$ and $9 \mathrm{~min}$ post-injection respectively). The rapid decrease in the gadolinium concentration in the tumor, which is in the same order of magnitude than the elimination time of the chelates from the blood, is problematic to determine the most suited moment for irradiation (i.e. higher content of gadolinium in the tissue combined to the lower one in the surrounding healthy tissues).

AGuIX nanoparticles accumulate passively in tumors thanks to the enhanced permeability and retention effect (EPR effect) [36], firstly described by Maeda et al. [18]. In the specific case of brain, the nanoparticles and the chelates cannot cross the blood brain barrier unless it is compromised by a pathology like a tumor. The DTPA based AGuIX nanoparticles have previously shown passive accumulation in 9LGS gliomabearing rats [27]. This specific gliosarcoma model has been chosen due to its characteristics close to human gliomas (high proliferative capability, high vascularization and high infiltrative pattern) [33]. DOTAGA based AGuIX nanoparticles have been injected 
intravenously in two 9LGS glioma-bearing rats. The temporal evolutions of the $\mathrm{T}_{1}$ signal have been observed in both rats and are completely similar. It is then shown in Figures 2 and 3 for only one of the rats.

A small increase in the signal was observed in the healthy tissue of the rats, followed by a rapid decrease a few minutes after the injection. Conversely, a significant enhancement of the MRI signal was noticed in the tumor. It reached a plateau about 7 minutes after the intravenous injection of the nanoparticles (See Figure 3). After 1 day, a weak MRI signal can be still visualized in the tumor due to the presence of the nanoparticles (See Figure 4). The persistence of the signal is due to the very slow leakage of the nanoparticles from the tumor. The capacity of the nanoparticles to remain in the tumor even hours after their injection is a real asset to determine an adapted radiotherapy protocol. Contrary to the gadolinium chelates that present a rapid elimination from the tumor, the nanoparticles are rapidly cleared from healthy tissues while conserving a high and relatively constant concentration in the tumor.

\section{In vivo radiosensitization survival curves}

A comparison was performed between the efficiencies of molecular complexes, such as gadolinium chelates (DOTAREM ${ }^{\circ}$ ) and of chelates incorporated at the surface of ultrasmall nanoparticles (AGuIX), under the same irradiation conditions, i.e. $20 \mathrm{~min}$, after intravenous injection. The short delay of $20 \mathrm{~min}$ has been chosen to maintain a relatively high gadolinium concentration in the tumor during irradiation when using the chelates. In a first experiment, two experimental conditions were tested for the chelates. The same quantity of gadolinium $(56 \mu \mathrm{mol})$ was injected in all the experiments. For the chelates, two different gadolinium concentrations were used: (i) $\left[\mathrm{Gd}^{3+}\right]=1 \mathrm{M}$ (injected volume of $56 \mu \mathrm{L}$ ), close from the concentrations used for DOTAREM $^{\circ}$ in clinic protocol and (ii) $\left[\mathrm{Gd}^{3+}\right]=40 \mathrm{mM}$ (injected volume of $1.4 \mathrm{~mL}$ ), the concentration used with nanoparticles. These two different concentrations were used in order to determine if the initial concentration of the solution has an influence upon the survival curves (See Figure 5). Regardless of the concentration, almost no difference is observed between the survival curves when the irradiation is performed in presence or in

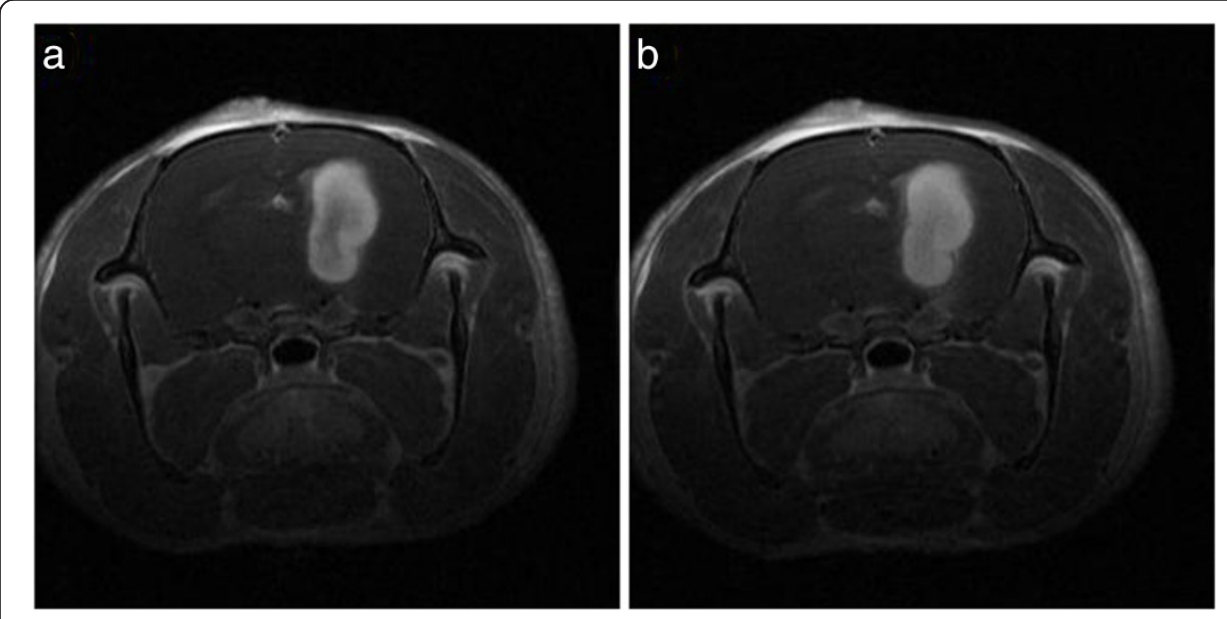

Figure $2 T_{1}$-weigthed images of the brain of a $9 L$ bearing rat: a) 7 and b) 11 minutes after intravenous injection of AGuIX nanoparticles. 


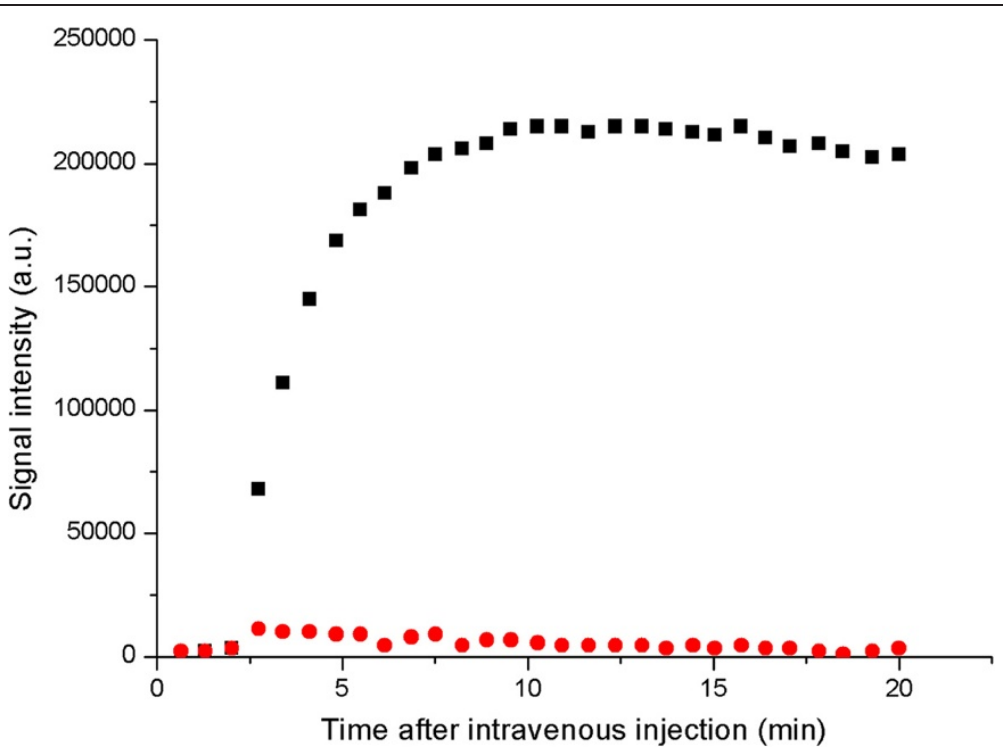

Figure 3 Temporal evolution of the MRI signal in tumor (black squares) and in an equivalent surface in normal tissue in the left hemisphere (red circles).

absence of chelates (MeST were equal to 32 and 43 days for chelates and 44 days for irradiation only) (See Table 1). These median survival times are higher than for nontreated animals (MeST of 19 days). This corresponds to an increase in lifespan (ILS) of $131 \%, 126 \%$ and $68 \%$ for irradiation alone or in presence of gadolinium chelates injected 20 minutes before at $\mathrm{Gd}$ concentrations of $40 \mathrm{mM}$ and $1 \mathrm{M}$ respectively.

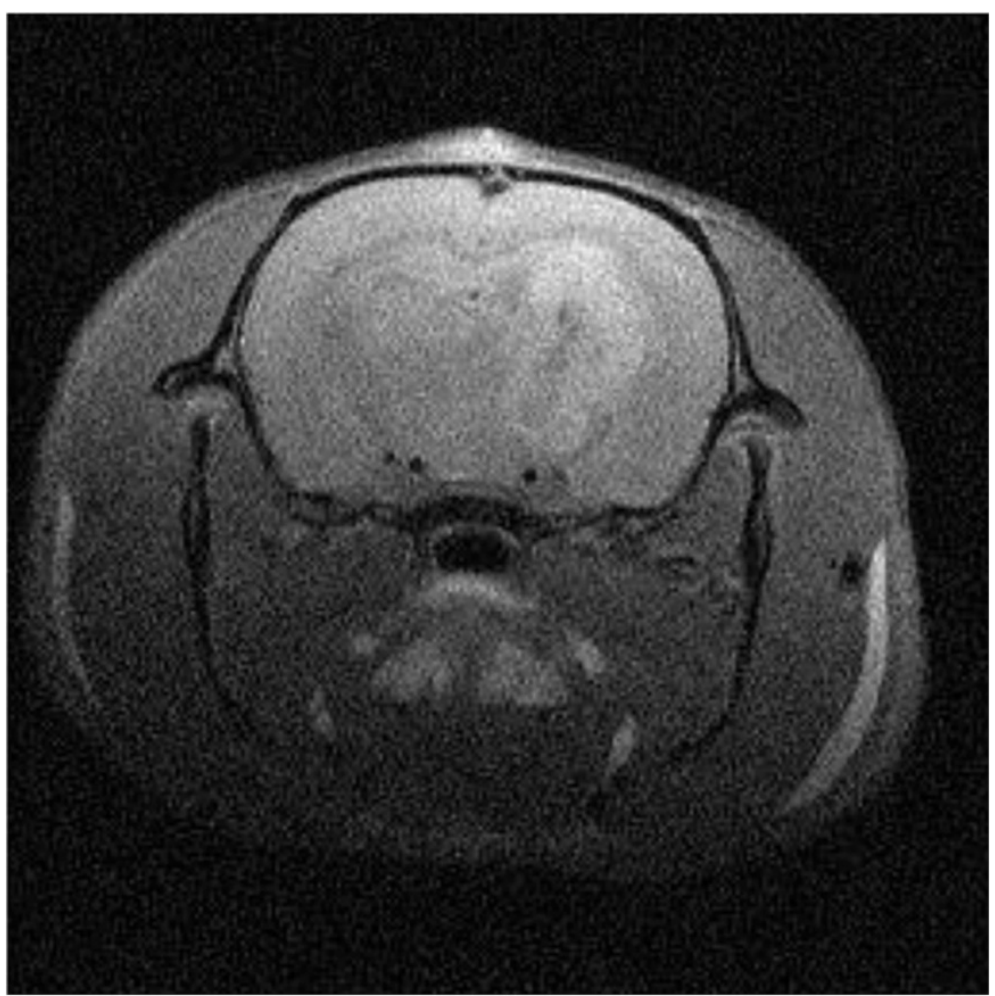

Figure $4 \mathrm{~T}_{1}$-weigthed images of the brain of a 9LGS bearing rat 1 day after intravenous injection of AGulX nanoparticles. 


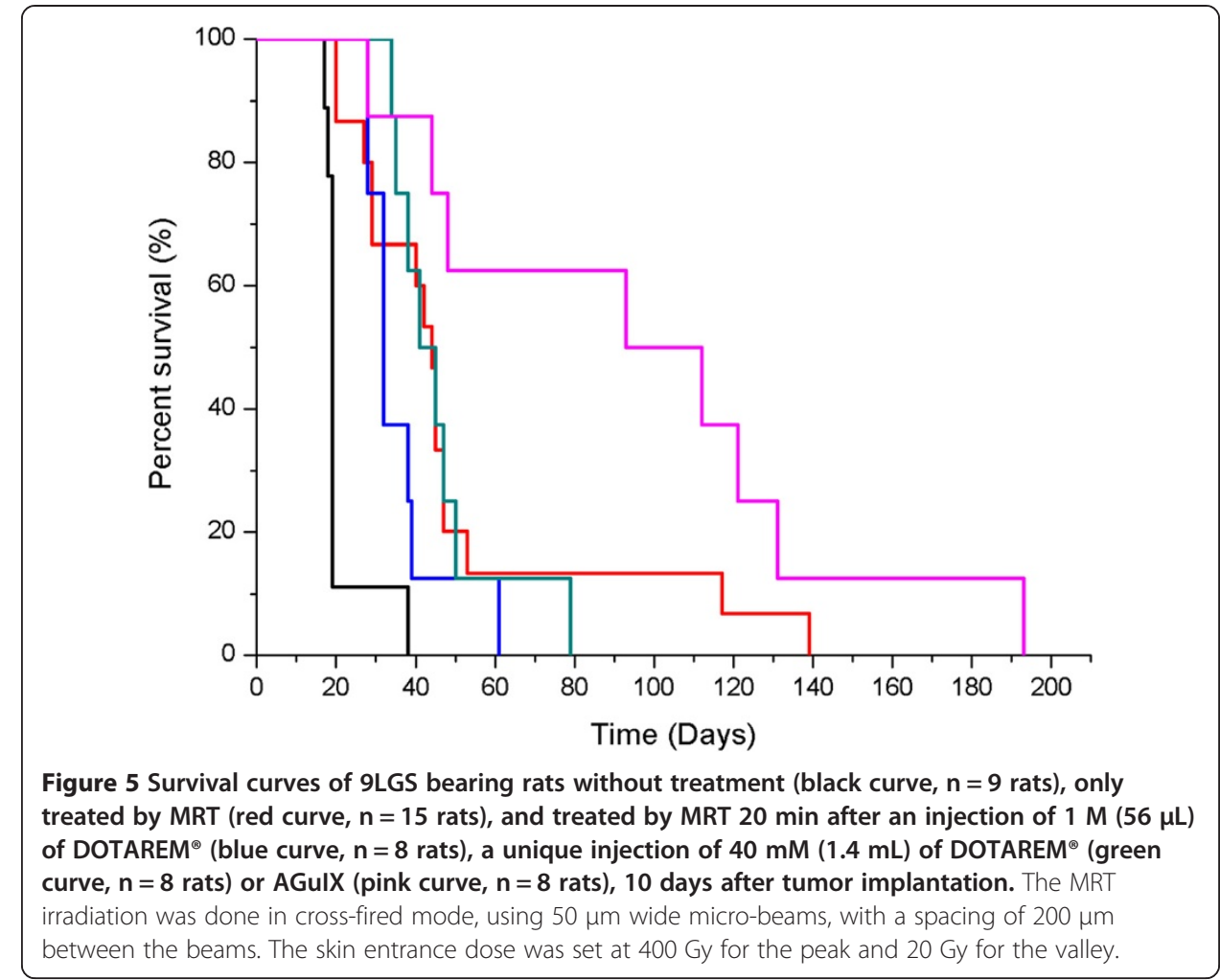

In comparison, the irradiation of the animals $20 \mathrm{~min}$ after the intravenous injection of the AGuIX nanoparticles $\left(1.4 \mathrm{~mL}\right.$ and $\left.\left[\mathrm{Gd}^{3+}\right]=40 \mathrm{mM}\right)$ with the same amount of gadolinium than after injection of DOTAREM ${ }^{\circ}$ leads to an important increase of the MeST to 102.5 days. It corresponds to an impressive ILS of 439\%. A significant difference is found between particles and chelates associated to MRT ( $<0.0035$ and $p$ $<0.0158$ for the $1 \mathrm{M}$ injection and the $40 \mathrm{mM}$ injection using the log rank test).

\section{Conclusion}

To conclude, the treatment of glioma bearing rats with MRT after injection of AGuIX nanoparticles leads to an important increase in the survival of aggressive glioma bearing rats. On the contrary, no evidence of such increase has been observed with the combination of MRT and gadolinium chelates. The accumulation of particles in brain

Table 1 MeST of the 9LGS bearing rats without irradiation, after MRT irradiation (i) only, (ii) in presence of DOTAREM ${ }^{\oplus}$ and (iii) in presence of particles (with the same quantity of gadolinium)

\begin{tabular}{lcc}
\hline & Median survival time (Days) & Number of rats \\
\hline Without irradiation & 19 & 9 \\
Only MRT & 44 & 15 \\
MRT irradiation 20 minutes after injection of $56 \mu \mathrm{L}$ of & 32 \\
DOTAREM ${ }^{\circledast}\left([\mathrm{d}]^{3+}=1 \mathrm{M}\right)$ & \\
MRT irradiation 20 minutes after injection of $1.4 \mathrm{~mL}$ of & 43 \\
DOTAREM $\left.{ }^{\circledast}\left([\mathrm{Gd}]^{3+}=40 \mathrm{mM}\right]\right)$ & \\
$\begin{array}{l}\text { MRT irradiation } 20 \text { minutes after injection of } 1.4 \mathrm{~mL} \\
\left.\left.\text { of AGulX nanoparticles ( }[\mathrm{Gd}]^{3+}=40 \mathrm{mM}\right]\right)\end{array}$ & 102.5 \\
\hline
\end{tabular}


tumor is different than that of commercial chelates, presenting a fast accumulation but also a strong residence time in the tumor; they remain for hours after the injection. The plateau of MRI signal observed in the tumor, which can be linked to the gadolinium concentration, is of importance for radiotherapy as irradiation can be performed after the elimination of the nanoparticle from the blood circulation, while conserving about the same quantity of nanoparticles in the tumor. The particles allow a biodistribution that is very well suited for an optimal radiosensitization, thanks to the EPR effect previously mentioned. The particle aspect of the AGuIX is now proven to provide nanodose energy deposition in the vicinity of the nanoparticles. This deposition is due to a series of absorption/emission of Auger electrons that take place within the particles (also called Auger shower) between the $\mathrm{Gd}^{3+}$ cations permitting the initiation of deleterious phenomena absent with commercial gadolinium chelates. Therefore AGuIX nanoparticles present the characteristics of an adapted drug for theranostic applications: contrast enhancement for MRI due to high relaxivity, high radiosensitizing properties and adapted biodistribution (i.e. elimination by the kidneys and passive accumulation in the tumor).

\footnotetext{
Competing interests

S. Roux, P. Perriat, F. Lux and O. Tillement have filed an international patent on the synthesis and the characterization of the AGulX nanoparticles (WO2011135101A2). The authors declare that they have no competing interests
}

\section{Authors' contribution}

This manuscript is issued from a collaborative work between teams working in nanoparticle synthesis, in physical characterization, in MR imaging and in radiotherapy. This collaboration between physicists, chemists, biologists and clinicians explain the important number of contributors. AP-T is involved in the synthesis and the characterization of the nanoparticles $C T$ and $A M$ are involved in the characterization of the biodegradability of the nanoparticles. $F L$ and OT are the supervisors of AP-T, CT and AM. They supervised all the experimental procedures and are involved in the manuscript preparation and revision. PP is involved in the characterization of the nanoparticles and has participated to the preparation and the revision of the manuscript. LS and SD participate to the imaging part of the manuscript. SR, GLD and EB are involved in all the irradiation protocols. GLD participated to the manuscript elaboration. All authors read and approved the final manuscript.

\section{Acknowledgements}

This work was supported by the LABEX PRIMES (ANR-11-LABX-0063) of Universite de Lyon, within the program "Investissements d'Avenir" (ANR-11-IDEX-0007) operated by the French National Research Agency (ANR), as well as the ANR TheraGulma (ANR-11-NANO-017). Thanks are also due to French program ANR-12-RPIB-0010 Multimage, to Grenoble MRI facility IRMaGE and to beamtime at the ESRF BioMedical beamline.

\section{Author details}

${ }^{1}$ ID17 Biomedical Beamline, European Synchrotron Radiation Facility, 6 rue Jules Horowitz, 38000 Grenoble, France. ${ }^{2}$ Institut UTINAM, UMR 6213 UFC-CNRS, Université de Franche-Comté, 16 route de Gray, 25030 Besançon, Cedex, France. ${ }^{3}$ Institut Lumière Matière, UMR 5306 Université Lyon 1 - CNRS, Team FENNEC, Université de Lyon, 69622 Villeurbanne, Cedex, France. ${ }^{4}$ Nano-H S.A.S, 2 Place de I'Europe, 38070 Saint Quentin-Fallavier, France. ${ }^{5}$ MATEIS, UMR 5510 INSA Lyon - CNRS, INSA Lyon, 69621 Villeurbanne, France.

Received: 21 March 2014 Accepted: 29 May 2014

Published: 1 July 2014

\section{References}

1. Stasiuk GJ, Long NJ (2013) The ubiquitous DOTA and its derivatives: the impact of 1,4,7,10-tetraazacyclododecane1,4,7,10-tetraaccetic acid on biomedical imaging. Chem Commun 49:2732-2746

2. Sherry AD, Caravan P, Lenkinski RE (2009) Primer on gadolinium chemistry. Magn Reson Med 30:1240-1248

3. Thomsen HS (2006) Nephrogenic systemic fibrosis : a serious late adverse reaction to gadodiamide. Eur Radiol 16:2619-2621

4. Chakraborty S, Shi J, Kim Y-S, Zhou Y, Jia B, Wang F, Liu S (2010) Evaluation of ${ }^{111}$ In-labeled cyclic RGD peptides: tetrameric not tetravalent. Bioconj Chem 21:969-978

5. Hong H, Yang Y, Zhang Y, Engle JW, Barnhart TE, Nickles RJ, Leigh BR, Cai W (2011) Positron emission tomography imaging of CD105 expression during tumor angiogenesis. Eur J Nucl Med Mol Imaging 38:1335-1343

6. Moreau M, Raguin O, J-M V, Collin B, Bernhard C, Tizon X, Boschetti F, Duchamp O, Brunotte F, Denat F (2012) DOTAGA-Trastuzumab. A new antibody conjugate targeting HER2/ Neu Antigen for diagnostic purposes. Bioconj Chem 23:1181-1188

7. Zhou Z, Wu X, Kresak A, Griswold M, Zheng-Rong L (2013) Peptide targeted tripod macrocyclic Gd(III) chelates for cancer molecular MRI. Biomaterials 34:7683-7693 
8. Rockey WM, Huang L, Kloepping KC, Baumhover NJ, Giangrande PH, Schultz MK (2011) Synthesis and radiolabelling of chelator-RNA aptamer bioconjugates with copper-64 for targeted molecular imaging. Bioorg Med Chem 19:4080-4090

9. Pagel MD (2011) The hope and hype of multimodality imaging contrast agents. Nanomedicine 6:945-948

10. Yamane T, Hanaoka K, Muramatsu Y, Tamura K, Adachi Y, Miyashita Y, Hirata Y, Nagano T (2011) Method for enhancing cell penetration of $\mathrm{Gd}^{3+}$-based MRI contrast agents by conjugation with hydrophobic fluorescent dyes. Bioconj Chem 22:2227-2236

11. Hall MA, Kwon S, Robinson H, Lachance P-A, Azhdarinia A, Ranganathan R, Price RE, Chan W, Sevick-Muraca EM (2012) Imaging prostate cancer lymph node metastases with a multimodality contrast agent. Prostate 72:129-146

12. Frullano L, Catana C, Benner T, Sherry AD, Caravan P (2010) Bimodal MR-PET agent for quantitative pH imaging. Angew Chem Int Ed 49:2382-2384

13. Alric C, Taleb J, Le Duc G, Mandon C, Billotey C, Le Meur-Herland A, Brochard T, Vocanson F, Janier M, Perriat P, Roux S, Tillement O (2008) Gadolinium chelate coated gold nanoparticles as contrast agents for both X-ray computed tomography and magnetic resonance imaging. J Am Chem Soc 130:5908-5915

14. Jarett BR, Gustafsson B, Kukis DL, Louie AY (2008) Synthesis of ${ }^{64}$ Cu-labeled magnetic nanoparticles for multimodal imaging. Bioconj Chem 19:1496-1504

15. Lux J, Chan M, Elst LV, Schopf E, Mahmoud E, Laurent S, Almutairi A (2013) Metal chelating crosslinkers form nanogels with high chelation stability. J Mater Chem B Mater Biol Med 46:6359-6364

16. Terreno E, Delli CD, Viale A, Aime S (2010) Challenges for molecular magnetic resonance imaging. Chem Rev 110:3019-3042

17. Ananta JS, Godin B, Sethi R, Moriggi L, Liu X, Serda RE, Krishnamurty R, Muthupillai R, Bolskar RD, Helm L, Ferrari M, Wilson LJ, Decuzzi P (2010) Geometrical confinement of gadolinium-based contrast agents in nanoporous particles enhances $\mathrm{T}_{1}$ contrast. Nat Nanotechnol 5:815-821

18. Maeda H (2010) Tumor-selective delivery of macromolecular drugs via the EPR effect : background and future prospects. Bioconjugate Chem 21:797-802

19. Petropoulos L, Seunders JK (2011) MRI and ultrasound guided treatment on a patient. US Patent 20110160566 A1

20. Pradhan AK, Naha SN, Montenegro M, Yu Y, Zhang HL, Sur C, Mrozik M, Pitzer RM (2009) Resonant X-ray enhancement of the auger effect in high-Z atoms, molecules, and nanoparticles: potential biomedical applications. J Phys Chem A 113:12356-12363

21. Hainfeld JF, Slatkin DN, Smilowitz HM (2004) The use of gold nanoparticles to enhance radiotherapy in mice. Phys Med Biol 49:N309-N315

22. Butterworth KT, McMahon SJ, Currel FJ, Prise KM (2012) Physical basis and biological mechanisms of gold nanoparticles radiosensitization. Nanoscale 4:4830-4838

23. Jain S, Coulter JA, Hounsell AR, Butterworth KT, MCMahon SJ, Hyland WB, Muir MF, Dickson GR, Prise KM, Currel FJ, O'Sullivan JM, Hirst DG (2011) Cell-specific radiosensitization by gold nanoparticles at megavoltage radiation energies. Int J Radiat Oncol Biol Phys 79:531-539

24. Young SW, Qing F, Harriman A, Sessler JL, Dow WC, Mody TD, Hemmi GW, Hao YP, Miller RA (1996) Gadolinium (III) texaphyrin: a tumor selective radiation sensitizer that is detectable by MRI. Proc Natl Acad Sci U S A 93:6610-6615, Erratum in: Proc. Natl. Acad. Sci. U. S. A., 1999, 96:2569

25. Dehnad H, Kal HB, Stam T, Gademan IS, van Moorselaar RJ, van der Sanden BP (2003) Response to motexafin gadolinium and ionizing radiation of experimental rat prostate and lung tumors. Int J Radiat Oncol Biol Phys 57:787-793

26. Francis D, Richards GM, Forouzannia A, Mehta MP, Khuntia D (2009) Motexafin gadolinium: a novel radiosensitizer for brain tumors. Expert Opin Pharmacother 10:2171-2180

27. Le Duc G, Miladi I, Alric C, Mowat P, Bräuer-Krisch E, Bouchet A, Khalil E, Billotey C, Janier M, Lux F, Perriat P, Roux S, Tillement O (2011) Towards an image-guided microbeam radiation therapy using gadolinium-based nanoparticles. ACS Nano 5:9566-9574

28. Lux F, Mignot A, Mowat P, Louis C, Dufort S, Bernhard C, Denat F, Boschetti F, Brunet C, Antoine R, Dugourd P, Laurent S, Vander EL, Muller R, Sancey L, Josserand V, Coll J-L, Stupar V, Barbier E, Rémy C, Broisat A, Ghezzi C, Le Duc G, Roux S, Perriat P, Tillement O (2011) Ultrasmall rigid platforms as multimodal probes for medical applications. Angew Chem Int Ed 51:12299-13303

29. Mignot A, Truillet C, Lux F, Sancey L, Louis C, Denat F, Boschetti F, Bocher L, Gloter A, Stephan O, Antoine R, Dugourd P, Luneau D, Novitchi G, Figueiredo LC, De Morais PC, Bonneviot L, Albela B, Ribot F, Van Lokeren L, Dechamps-Olivier I, Chuburu F, Lemercier G, Villiers C, Marche PN, Le Duc G, Roux S, Tillement O, Perriat P (2013) A top-down synthesis route to ultrasmall multifunctionnal Gd-based nanoparticles for theranostic applications. Chem Eur J 19:6122-6136

30. Eisenwiener KP, Powell P, Maecke HR (2000) A convenient synthesis of novel bifunctionnal prochelators for coupling to bioactive peptides for radiometal labelling. Bioorg Med Chem Lett 10:2133-2135

31. Bernhard C, Moreau M, Lhenry D, Goze C, Boschetti F, Rousselin Y, Brunotte F, Denat F (2012) DOTAGA-anhydride: a valuable building block for the preparation of DOTA-like chelating agents. Chem Eur J 18:7834-7841

32. Bridot J-L, Faure A-C, Laurent S, Rivière C, Billotey C, Hiba B, Janier M, Josserand V, Coll J-L, Vander Elst L, Muller R, Roux S, Perriat P, Tillement O (2007) Hybrid gadolinium oxide nanoparticles: multimodal contrast agents for in vivo imaging. J Am Chem Soc 129:5076-5084

33. Bouchet A, Bidart M, Miladi I, Le Clec'h C, Serduc R, Coutton C, Regnard P, Khalil E, Dufort S, Lemasson B, Laissue J, Pelletier L, Le Duc G Characterization of the $9 \mathrm{~L}$ gliosarcoma implanted in the Fisher rat : an orthotopic model for a grade IV brain tumor. Tumor Biol doi:10.1001/s13277-014-1783-6

34. Truillet C, Lux F, Tillement O, Dugourd P, Antoine R (2013) Coupling of HPLC with electrospray ionization mass spectrometry for studying the aging of ultrasmall multifunctional gadolinium-based nanoparticles. Anal Chem 85:10440-10447

35. Attenberger UI, Runge VM, Morelli JN, Williams J, Jackson CB, Mickaely HJ (2010) Evaluation of gadobutrol, a macrocyclic, nonionic gadolinium chelate in a brain glioma model: comparison with gadoterate meglumine and 
gadopentate dimeglumine at 1.5T, combined with an assessment of field strength dependence, specifically 1.5 versus 3T. J Magn Reson Imaging 31:549-555

36. Morlieras J, Dufort S, Sancey L, Truillet C, Mignot A, Rosseti F, Dentamaro M, Laurent S, Vander EL, Muller RN, Antoine R, Dugourd P, Roux S, Perriat P, Lux F, Coll J-L, Tillement O (2013) Functionnalization of small rigid platforms with cyclic RGD peptides for targeting tumors overexpressing $\alpha_{v} \beta_{3}$ integrins. Bioconjugate Chem 24:1584-1597

doi:10.1186/s12645-014-0004-8

Cite this article as: Le Duc et al: Advantages of gadolinium based ultrasmall nanoparticles vs molecular gadolinium chelates for radiotherapy guided by MRI for glioma treatment. Cancer Nanotechnology 2014 5:4.

Submit your manuscript to a SpringerOpen ${ }^{\circ}$ journal and benefit from:

- Convenient online submission

- Rigorous peer review

- Immediate publication on acceptance

- Open access: articles freely available online

- High visibility within the field

- Retaining the copyright to your article 